\title{
DIE RELIGIEUS-KULTURELE LEEFWYSE AS UITGANGSPUNT VIR ONDERWYSBEPLANNING
}

\author{
Jeannette Steyn \\ Departement Fundamentele en Historiese Opvoedkunde, PU vir CHO, \\ vaaldriehoekkampus
}

\section{ABSTRACT}

The discussion in this article centres on the hypothesis that the religious and cultural way of life, based upon the fundamental principle of universality and individuality, should be the point of departure in any type of educational planning. The bases of two education acts are discussed in the light of historical facts and the viewpoints of several authors, and considered in the perspective of the fundamental principle of universality and individuality.

The religious-cultural perspective as point of departure offers a solution to the problem of providing education to all people in the Republic of South Africa.

\section{INLEIDING}

In die Suid-Afrikaanse onderwysgeskiedenis is daar veral twee wette wat beleid neerlè oor die religieus-kulturele uitgangspunte vir die onderwys. Ten eerste stel Wet 39 van 1967 (vgl. Par. 3.3) een oorkoepelende uitgangspunt vir alle onderwysbelanghebbendes. Ten tweede vereis die Wet op die Nasionale beleid vir Algemene Onderwyssake (Wet 76, 1984:4) "dat erkenning aan sowel die gemeenskaplikheid as die diversiteit van die religieuse en kulturele leefwyse en aan die tale van die inwoners van die Republiek verieen moet word".

Tussen hierdie twee wette is daar oënskynlik 'n kontradiksie omdat Wet 39 ' $n$ uitgangspunt op alle lewensbeskoulike groeperinge in die samelewing van toepassing maak, terwyl Wet 76 die "religieuse en kulturele leefwyse" van verskillende groepe erken. Die kern problematiek setel dus rondom Koers 53(4) 1988 $-600-$ 
in verantwoorde onderwysbeplanning waar dit die religieus-kulturele aangaan. Wet 76 se religieuse en kulturele leefwyses word egter nie eenduidig deur kundiges, waar onder beleidmakers en akademici, geoperasionaliseer nie.

"Religieuse leefwyse" word onder andere op twee wyses in die onderwysgeskiedenis vergestait, naamlik op 'n Bybels-Christelikereligieuse wyse, soos byvoorbeeld geformuleer deur die Vereniging van Christelike Hoër Onderwys (vgl. Viljoen, 1984:66), of op in liberalisties-religieuse wyse, soos onder andere vergestalt in die denke van Hardman (1982:76) van die "Natal Teachers Association".

"Kulturele leefwyse" word onder andere op die volgende twee wyses vergestalt, naamlik in terme van 'n Suid-Afrikaanse kultuur (Ryman, 1983:148) en/of 'n volkseie kultuur (Kruger, 1986b:9).

"Religieuse leefwyse" sowel as "kulturele leefwyse" vertoon individuele sowel as universele grondtrekke. Volgens Taljaard (1975:62) vertoon alle entiteite in die werklikheid universele sowel as individuele grondtrekke wat gelyktydig voorkom en onlosmaaklik aan mekaar verbonde is en ook gelykwaardig is. Die universaliteit van 'n entiteit dui op die gemeenskaplikheid wat dit met ander dinge deel. So byvoorbeeld deel die mens sy mensheid met alle mense. Die individualiteit dui egter weer op die eiesoortigheid van dieselfde entiteit wat dit van ander dinge onderskei (maar nie skei nie). So byvoorbeeld besit elke mens 'n eie persoonlikheid wat individueel (uniek) aan daardie een mens is en hom onderskei van alle ander mense (Taljaard, 1975:63).

Wanneer die "kulturele leefwyse" slegs in 'n alles insluitende gemeenskaplike Suid-Afrikaanse kultuur geoperasionaliseer word, word die bestaan van verskillende eiesoortige kulturele leefwyses daarbinne weggedink. So gaan die individuele dan in die universele op en lei dit tot universalisme. Hierteenoor mag bepaalde denkers die verskillende kulturele leefwyses as sodanig eiesoortig of individueel operasionaliseer dat die gemeenskaplikheid of universele eienskappe daartussen, weggedink word. Hierdeur gaan die universele in die individuele op en is individualisme die gevolg. 
Om hierdie universeel-individuele-grondtrek van die religieuse en kulturele leefwyse as uitgangspunt in die onderwysbeplanning te ondersoek, sal soos volg te werk gegaan word:

"Kulturele leefwyse" as uitgangspunt vir beplanning in die onderwys word eerstens bespreek. Uit die literatuur sal lig gewerp word op die vergestaltinge in 'n "volkseie kultuur" teenoor " $n$ Suid-Afrikaanse kultuur" as vertrekpunt by onderwysvoorsiening. Tydens die bespreking sal aandag bestee word aan die probleem van die verhouding tussen die universele en individuele met betrekking tot die kulturele.

Ten tweede sal "religieuse leefwyse" bespreek word. Die verhouding tussen die universele en die individuele, soos hoërop gestel, sal ook hier aan die hand van relevante grepe uit die literatuur toegelig word.

Die betoog in hierdie artikel wentel rondom die hipotese dat die universeel-individueel-grondtrek van die religieus-kulturele lewenswyses van mense altyd die uitgangspunt in onderwysbeplanning vorm. Die begrip "religieus-kultureel" sal in die proses toegelig word.

\section{DiE "kUlturele Leefwyse" as uitgangspunt ViR} ONDERWYSBEPLANNING

\subsection{Die begrip "kultuur"}

Steyn (1984:2) meen tereg dat daar net soveel interpretasies van die begrip kultuur bestaan as wat daar verskillende kulture bestaan. Na bestudering van De Klerk et al. (1972:228); Heyns (1974:31); Vogelaar E Bregman (1984:31), Banks \& Lynch (1986:69) en Ellis et al. (1986:188), is die volgende wesenstrekke van "kultuur" vasgestel:

- Die mens gebruik die natuur om kultuur te skep ("colere" die Latynse oorsprong vir grondbewerking).

- Die omskepping van natuur in kultuur veronderstel 'n handelende aksie ("colo" die Latynse oorsprong vir bou). 
- Die resultaat van die handeling word gestempel deur die groep mense wat kultuur aanwend.

- Sodanige stempel dra in sosiale, etiese en religieuse karakter wat kenmerkend van dié bepaalde gemeenskap se gedragspatroon, gewoontes en omstandighede is.

Vir die doel van hierdie artikel word kultuur gesien as 'n samehang van genoemde wesenstrekke.

\section{2 in Suid-Afrikaanse kultuur}

Ryman (1983:148) bepleit 'n Suid-Afrikaanse kultuur ("nationalism") in die onderwys omdat al die volke in Suid-Afrika algemene menslikheid en in gemeenskaplike land het.

Hierdie aandrang op 'n Suid-Afrikaanse kultuur met sy algemene menslikheid en gemeenskaplike land is egter gefundeer op 'n verabsolutering van die gemeenskaplike of universele in die beplanning van die onderwys. Met die verabsolutering van 'n algemene Suid-Afrikaanse kultuur word die kultuureie (individuele) van bepaalde volke onderbeklemtoon en in smeltkroes van eie kulture in die onderwysstelsel veronderstel.

Die geskiedenis van die onderwys lewer getuienis teen sodanige veralgemeende kultuurbeskouing. Die mislukte verengelsingsbeleid van Lord Charles Somerset in 1806 (Van der Walt, 1984:75-76) spreek duidelik van 'n universalistiese siening. Lategan $(1952: 45)$ is van mening dat sy oorbeklemtoning van die universele die individuele in reaksie na vore geroep het: "Suid-Afrikaanse nasionalisme kom tot uiting in die negentiende eeu met die ontaktiese optrede van die Imperialiste en Liberaliste wat gebruike van die Kerk en tradisies van die volk wou omskep en verander sodat land, volk en kerk mettertyd sy eiendomlikheid en karakteristieke kenmerke en eienskappe moes verloor".

Steyn (1984:22) bevind dat onderwysbeplanners ook in die VSA nie daarin kon slaag om verskillende kultuurgroepe in 'n homogene "Amerikanisme" te laat opgaan nie, en White (1983:159) betwyfel die moontlikhede tot $-603-$ 
sukses van 'n algemene "nationa education". Hy sè dat daar geen ander land in die wêreld is waar daar minder kans op welslae is vir só 'n stelsel as juis in die Republiek van Suid-Afrika nie en wel vanweë die blanke, Indiër-, gekleurde, Xhosa-, Zulu- en Sotho-kultuur. Selfs onder die blankes bestaan daar nie homogeniteit nie (blanke Engelssprekendes en blanke Afrikaanssprekendes).

Op grond van genoemde bevindings kan die gedagte van 'n SuidAfrikaanse kultuur as uitgangspunt vir onderwysbeplanning dus nie sonder meer aanvaar word nie.

\subsection{Volkseie kultuur}

Die volkseie vind vergestalting in die onderskeibare Afrikaanse, Engelse of Zoeloe-kultuur wat binne in Suid-Afrikaanse kultuur bestaan.

Volgens Stone (1984:97-104) en Dooyeweerd (1979:66-87) word die bestaansreg van ' $n$ volk gemeet aan die mate waarin die drie beginsels van individualiteit, integrasie en historiese deurlopendheid (kontinuïteit) gestalte gekry het. Hierdie drie beginsels sal ter toeligting bespreek word.

- Met individualiteit word bedoel dat die inhoud, aard en wese van sodanige volkskultuur gerig word deur die lewensbeskouing wat uniek aan die betrokke volk is. Op grond van die unieke, eiesoortigheid van die volk word 'n bepaalde volkskultuur onderskei van ander volkseie kulture.

- Integrasie van 'n volkseie kultuur vind plaas in die kontak met ander kulture. Nuwe kultuuraspekte word in die verrykingsproses in ' $n$ bestaande kultuur opgeneem slegs wanneer dit by die bestaande kultuur inpas en nie bots met die bestaande kultuur se lewensbeskouing nie.

- Die historiese of kontinue beskawingsbeginsel lè die deurlopende karakter van 'n volkseie kultuur ten grondslag. Die historiese verloop 
en vorming van ' $n$ volkseie kultuur bestaan as individuele aspek binne elke afsonderlike kultuur.

Uit die genoemde beginsels word afgelei dat die volkseie kultuur in individuele (individualiteits-) karakter dog tegeiyk ook in universele (integrerende) karakter besit in die sin dat genoemde beginsels by alle kulture voorkom. Nie een van hierdie beginsels mag verabsoluteer word nie.

Die volgende greep uit die geskiedenis toon as 'n kultuurhistoriese feit dat verskeie volkseie kulture bestaan. Kommisaris J. A. de Mist wou in 1802 in Betaafs-Hollandse kultuur afdwing deur sy primere doelstelling van die vorming van Hollandse burgers. Hy het hom egter misreken met die Afrikaanse volkseie kultuur wat reeds gevorm was en bestaansreg geopenbaar het. Die mislukte "melting-pot" in die VSA (Steyn, 1984:22) dien as verdere bewys hiervan.

Volgens Kruger (1986a:6) moet veranderings in ' $n$ bestaande kultuur altyd van binne-uit geskied, sodat dit op die grondslag van die bestaande kultuur kan plaasvind en nie revolusionère aksies teweegbring nie.

Juis die teenoorgestelde van wat Kruger (1986a:6) sè, vind in die geval van Wet 39 van 1967 plaas deurdat alle volkseie blanke kulture onder die Christelik-nasionale onderwysbeleid ingedwing is. Viljoen (1984:66) spreek hierdie probleem aan as hy aanvoer dat geen owerheid gewetensdwang op hierdie wyse mag toepas nie. Sodanige optrede veroorsaak dat die individuele karakter van 'n ander volkseie kultuur onderbeklemtoon of misgekyk word en universalisme dus intree.

Deur al dié argumente met betrekking tot volkseie kultuur, word die hipotese verder gestaaf: die universeel-individueel-grondtrek behoort in onderwysbeplanning erken te word. 


\section{3. "RELIGIEUSE LEWENSWYSE" AS UITGANGSPUNT IN}

ONDERWYSBEPLANNING

3.1 Die begrip "religie"

Die Latynse oorsprong van die woord "religie" naamlik re en ligare verwys as terug en bind: ' $n$ Verbinding aan die ware Oorsprong van die mens (aan God, dus anastaties-teosentries) of verbinding aan ' $n$ vermeende oorsprong (apostaties en gewoonlik humanisties) (Van der Walt et al., 1985:3).

Dit beteken dat religie beslag lè op die mens se geestelike sentrum (sy persoonlikheid of "ek") en daardeur die grondslag van alle menslike handelinge vorm.

Die betekenis hiervan is dat die mens se denke, handelinge en resultate van handelinge (soos kultuur) uitvloeisels vorm van 'n allesbeheersende religieuse gerigtheid. Alle uitgange van die mens word bepaal deur sy religie; sy kultuur en ook opvoedende onderwys kan dus nie anders as om religieus-bepaald te wees nie.

\subsection{Liberalistiese uitgangspunte}

Die liberalistiese uitgangspunte vorm 'n lyn deur die Suid-Afrikaanse onderwysgeskiedenis. Die eerste figure wat hierdie standpunte laat wortel skiet het, is De Mist (1804), Somerset (1806), Burgers (1874) en Smuts (1907) (Van der Walt, 1984:78).

In die soeke na 'n filosofiese onderbou vir die onderwys vir die Engelse volkseie kultuur, bepleit Hardman (1982:76) dat die liberalistiese en die rasionele die uitgangspunt moet wees van die onderwys.

Deur die rasionele as lewensopvatlike anker vir die onderwys te erken, plaas Hardman haar vertrekpunt in die tydelike rede van die mens. Die rasionele verwys immers na geloof in die menslike rede en sodoende word die analitiese vermoë of funksie van die mens die uitgangspunt wat die hele opvoedingsituasie religieus rig.

$-606-$ 
In die navorsing wat deur Postma $(1984: 42,43)$ van stapel gestuur is oor die religieuse grondmotief van die Transvaalse Onderwysvereniging (TO), is bevind dat die humanisties-liberalistiese lewensbeskouing die karakteristieke stempel was van die onderwys van die Engelsgeoriënteerde kultuur wat aan die Witwatersrand gevestig is, na die ontdekking van goud.

Dit is egter nie die doel met hierdie artikel om die religieuse raamwerk van die Engelse kultuureie te probeer bepaal en omlyn nie. Wat egter duidelik is, is dat toonaangewende persoonlikhede uit Engelse geledere (White, 1983; Ryman, 1983; Hardman, 1982; Ashley, 1982) dit met mekaar eens is dat die onderwys vir Suid-Afrika nie slegs vanuit 'n AfrikaansChristelike volkseie lewensopvatting beplan kan word nie.

3.3 Moet alle onderwys in Suid-Afrika dan vanuit 'n Christelike uitgangspunt beplan word?

Met die staatkundige eenwording van die Unie van Suid-Afrika in 1910 is uitgegaan van 'n Christelik-nasionale lewensbeskouing in die ZuidAfrikawet (1909). Christelik-nasionale onderwys is statutêr eers met Wet 39 van 1967 (die De Klerkwet) vir blankes ingevoer (Kruger, 1986a:7). Die De Klerkwet bepaal onder andere:

- Dat onderwys 'n Christelike karakter moet hê, maar dat die gelowe van ouers en kinders gerespekteer moet word ten opsigte van godsdiensonderrig en godsdienstige seremonies.

Teenkanting teen Christelik-nasionale onderwys het veral vanuit Engelse geledere gekom. Van den Berg $(1983: 72)$ meen byvoorbeeld dat die Christelike karakter van die Afrikaner 'n manier is om die mantel te keer na die wind vanwaar dit ook al mag kom. Hy beweer dat aan die een kant gesê word dat die Christelike karakter beteken om alles wat volkseie kultuur is, lief te hé en om net die volgende oomblik alle onderwys onder die Christelik-nasionale wet in te dwing. Volgens hom bied die sogenaamde Christelike roeping waaronder bewindhebbers in Suid-Afrika staan, slegs ' $n$ verskoning om die Christelike karakter in die onderwys op alle volkseie kulture af te dwing. 
Die individuele volkseie karaktertrek van die blanke Afrikaner word dus tot individualisme verabsoluteer omdat dit eensydig toegepas is en word.

In dieselfde trant verwys Ellis (1983:62) na die Christelik-nasionale karakter van die onderwys as in wet wat slegs op papier staan en dus nie eksplisiet in die klaskamer gesien kan word nie en daarom goedskiks verwyder kan word.

Die Christelik-nasionale uitgangspunt in die onderwys impliseer vir Morrow (1984:37) dat slegs die "outstanding", dit wil sè kulture wat aan bewind of in beheer van die onderwys staan, hul eie religieuse opvoedingsuitgangspunte kan uitleef. Hy sien dus tereg hierin die verabsolutering van die individuele van een groepering in die onderwys wanneer die Christelik-nasionale vir alle onderwysvraendes deur die wet vereis word.

Viljoen (1984:68) het ook 'n probleem met die Christelike as uitgangspunt in die beplanning van onderwys in dif RSA. Hy beskou die Christelike uitgangspunt vanuit staatkundig-politieke oogpunt, naamlik dat die bevordering van Christelike onderwys in staatskole teen die demokratiese gedagte van godsdiensvryheid indruis. Hy beredeneer die aspek verder deur aan te toon dat ook die Jood, Moslem en ateïs belasting betaal in die RSA en te vra of hulle dan nie ook geregtig op hulle waardes in die onderwys is nie.

Uit voorgaande beredenering kan tot die gevolgtrekking gekom word dat alle onderwys in die RSA nie vanuit Christelike uitgangspunt beplan kan word nie, maar wel volgens die religieus-kulturele uitgangspunt.

\section{GEVOLGTREKKING}

Vanuit die beredeneerde standpunt hierbo kan tot die volgende gevolgtrekkings aangaande die vraag na 'n uitgangspunt vir die beplanning van die onderwys in die RSA gekom word.

Wet 39 van 1967 is namlik gefokus op die bevordering van die religieuse uitgangspunt van een volkseie kultuur, naamlik dié van die blankes en $-608-$ 
in die besonder van die Afrikaner wat hom verbind het aan die BybelsChristelike uitgangspunt in die onderwys. Hierdie Christelik-Afrikaanse beginsel is foutiewelik afgedwing op alle blanke onderwys in die RSA, en dusdoende is in individualisme verval.

Wet 76 van 1984 bring egter ewewig enersyds vir die Christen wat die ideaal nastreef van Christelike onderwys in Christelike skole vir Christelike kinders, en andersyds word ook ruimte gelaat vir ander religieus-kultuureie groepe om hulle eie skole daar te stel, dus 'n eie religieus-kulturele uitgangspunt in die onderwys te stel.

Daar is dus wesenlik gevorder op die pad van reformasie in die onderwys deurdat die individualistiese oorbeklemtoning van wet 39 in ewewig gebring is deur die erkenning van tegelyk die universele en individuele of, soos Wet 76 dit stel, van die "gemeenskaplikheid en diversiteit".

Uit voorgaande beredenering het dit duidelik geblyk dat die religieuskulturele die uitgangspunt in die beplanning van die onderwys moet wees. Deur erkenning van tegelyk die universele en individuele van alle lewensopvattings ingevolge Wet 76 van 1984, word die verantwoordelikheid in die hand geplaas van die ouer (wat aan sy kind opvoedende onderwys wil voorsien), die onderwyser (wat met opvoedende onderwys gemoeid is) en elke burger van Suid-Afrika (wat onderwys in die RSA tot die optimale ontwikkel wil sien).

Weliswaar sal daar nog talle belemmerende faktore veral in die praktiese toepassing van die beginsel universeel-individueel, bestaan. Die mening word egter gehuldig dat sodanige probleme opgelos kan word deur elke skool se ouerkorps toe te laat om sy eie religieus-kulturele oortuigings in die skool te laat uitleef. Dit bly die verantwoordelikheid van die ouer om sy kind in te skryf in ' $n$ skool waarvan die oortuigings in lyn is met sy eie.

Die religieus-kulturele as uitgangspunt blyk dus 'n oplossing te wees in die voorsiening van die onderwys vir alle mense in die Republiek van Suid-Afrika. 
BIBLIOGRAFIE

ASHLEY, M. 1982. Change education philosophy in South Africa. Mentor, 64(3):77-78.

BANKS, J.A. \& LYNCH, J. 1986. Multicultural education in western societies. London : Holt, Rinehart and Winston Ltd.

DE KLERK, W.J., DUVENAGE, B. \& VAN WYK, J.H. 1972. Roeping en werklikheid. Potchefstroom: Herald (Edms) Bpk.

DOOYEWEERD, H. 1979. Roots of Western Culture ('n Vertaling deur Kraay, J.) Toronto : Wedge Publishing Foundation.

ELLIS, M.J. 1983. From the president. Mentor, 65(2):59-64.

ELLIS, A.K., DOGAN, J.J. E HOWEY, K.R. 1986. Introduction to the foundation of education. USA : Prentice Hall.

HARDMAN, Pixie. 1982. I just want to say. Mentor, 64(3):76.

HEYNS, J.A. 1974. Die mens: Bybelse en buite-Bybelse mensbeskouinge. Bloemfontein : Sacum Beperk.

KRUGER, H.B. 1986a. Bybelse beginsels vir Christelike-volkseie opvoeding en onderwys. Referaat gelewer by die Afrikaner Onderwyskongres vir SWA te Windhoek, 18 en 19 April 1986.

KRUGER, H.B. 1986b. Die toepassing van die Christelikevolkseielewensbeskouing binne gesins-, sosiale en volksverband. Referaat gelewer by die Afrikaner Onderwyskongres vir SWA te Windhoek, 18 en 19 April 1986.

LATEGAN, D. 1982. Na driehonderd jaar. Gereformeerde Vaandel, 20(2) : 43-97.

MORROW, W.E. 1983. 'Philosophies of education' in SA. Part 1. South African Journal of Education, 4(1):37.

$-610-$ 
POSTMA, W. 1984. The dynamis underlying the origin, the history, and the function of the TO. South African journal of Education, $4(1): 41-45$.

RYMAN, F.D. 1983. The president's address. Mentor, 65(3):148-150.

STEYN, H.J. 1984. Kultuurdifferensiasie in die onderwys. Potchefstroom : Navorsingsverslag van die RGN/PU vir CHO.

STEYN, I.N., VAN DER WALT, J.H.P., DEKKER, E.L. \& STEYN, H.J. 1982. Opvoeding in tydsperspektief. Potchefstroom : Wesvalia.

STONE, H.J.S. 1984. Gemeenskaplikheid en diversiteit. 'n Profiel van die Vergelykende Opvoedkunde. Johannesburg : Mc Graw-Hill.

SUID-AFRIKA (Republiek) 1984. Wet op die Nasionale beleid vir Algemene Onderwyssake, no, 76 van 1984. No. 9292. Pretoria : Staatsdrukker.

TALJAARD. J.A.L. 1975. in Skrifmatige synsleer. Potchefstroom : PU vir CHO. (Diktaat 21/75.)

VAN DEN BERG, D. 1983. Christian national education and the youth preparedness programme: the total onslaught reaches the schools. Mentor, 65(2): 70-76.

VAN DER WALT, J.H.P. 1984. Verband tussen religie, kultuur en opvoedende onderwys in die skool in historiese perspektief. Potchefstroom : Navorsingsverslag van die RGN/PU vir CHO.

VAN DER WALT, J.L., DEKKER, Elise, I. \& VAN DER WALT, I.D. 1985. Die opvoedingsgebeure. in Skrifmatige perspektief. Potchefstroom : PU vir CHO.

VILJOEN, G. van N. 1984. Die owerheid en Christelike onderwys. (In Bakens en uitdagings vir ons onderwys. Pretoria : Departement van Nasionale Opvoeding. 88p.) 
VOGELAAR, D. \& BREGMAN, C. 1984. School, maatschappij en cultuur in Bijbels licht. Hendrik Ido Ambacht : Begeleidingscentrum Gereformeerd Schoolonderwijs.

WHITE, D. 1983. The role of the English speaking teacher's associations in South African society. Mentor, 65(3): 158-161. 